\title{
Organizational Culture and Knowledge Sharing Behavior: Examining Serial Mechanisms
}

\author{
Saliha Gul Abbasi ${ }^{1 *}$, Ghulam Dastgeer ${ }^{1}$
}

\begin{abstract}
This study aims to examine how hierarchy organizational culture affects the knowledge sharing behavior of teachers in higher education institutions and universities and its mediated link through formal knowledge governance mechanism and knowledge sharing opportunity. A sample of 269 teachers was drawn from university teachers in Pakistan and structural equation modeling is used to test the hypotheses. The results of this study suggest that first, hierarchy organizational culture is positively associated with knowledge sharing behavior of teachers. Second, formal knowledge governance mechanism fully mediated the relationship between hierarchy organizational culture and knowledge sharing behavior. Third, knowledge sharing opportunity fully mediated the relationship between hierarchy organizational culture and knowledge sharing behavior. Finally, the relationship between hierarchy organizational culture and knowledge sharing behavior is sequentially and fully mediated by formal knowledge governance mechanism and knowledge sharing opportunity. Theoretical and managerial implications are discussed followed by limitations of the study along with suggestions for future research.
\end{abstract}

Keywords: Formal Knowledge Governance Mechanism, Hierarchy Organizational Culture, Knowledge Sharing Behavior, Knowledge Sharing Opportunity.

JEL Classification: M140, M150.

\section{Introduction}

Knowledge sharing, one of the core processes of knowledge management, is recognized as a source of competitive advantage in the market where competitiveness and dynamic economy are the driving factors to achieve an edge (Wang \& Noe, 2010). Nonaka (1994) suggested that efficient information handling and decision making are important for an organization's survival in a changing, complex and uncertain environment. Study of the processes and mechanisms through which an organization creates and transfers knowledge would help to understand the operations of an organization under uncertain conditions and its interactions with environment (Nonaka, Byosiere, Borucki, \& Konno, 1994).

Corresponding Author: salihagul.uajk@gmail.com

${ }^{1}$ Air University School of Management 
Knowledge sharing is hard to achieve without involving people Yang (2010), Amayah (2013), Akhavan, Hosseini, Abbasi, and Manteghi (2015). Opportunities provided for transferring knowledge are also important as social exchange perspective suggests the vitality of opportunities in an organization for exchange of knowledge (Argote, McEvily, \& Reagans, 2003; Huang, Chiu, \& Lu, 2013). Few studies have been done in public sector examining knowledge sharing behavior (Singh Sandhu, Kishore Jain, and Ahmad (2011); Amayah (2013); Yusof, Ismail, Ahmad, and Yusof (2012)). Knowledge sharing is influenced by the mode of transmission of knowledge from the source and the motivational disposition (Cabrera \& Cabrera, 2005; Huang et al., 2013; LopezNicolas \& Meroño-Cerdán, 2009).

The importance of KS has been acknowledged at several KM platforms and in special issues on KS in the top ranking journals in the field of KM. Personal benefits, normative and community related considerations provide opportunities associated with knowledge sharing willingness (Ardichvili, 2008; Amayah (2013)). Employees will not engage in voluntary behaviors like knowledge sharing, if the organizational environment is not encouraging (Yang, 2007). An environment that encourages knowledge sharing facilitates interaction among employees (Amayah, 2013).

Availability of knowledge to others in the organizations is knowledge sharing (Ipe, 2003) and implementing governance mechanisms to capture, store, create and use knowledge is knowledge governance (Foss, Mahoney, \& De Pablos, 2010; Huang et al., 2013). Knowledge governance has a pivotal role in knowledge sharing (Husted, Michailova, Minbaeva, \& Pedersen, 2012). Extent literature on the area established that KGMs encourage knowledge sharing (Anne Crowne (2009); Liu and Liu (2011)) but other studies report the contrary findings (Huang et al., 2013). Due to inconsistent findings, the area focusing on how knowledge governance processes influence knowledge sharing behavior is underexplored. Organizational culture is a major contributing factor to transfer knowledge and to shape knowledge sharing behavior among individuals (Huang et al., 2013). This study utilizes social exchange perspective along with social identity theory to explain the mechanisms and motivations that facilitate knowledge sharing among organizations.

Knowledge sharing influences the performance of organizations in both public and private sector (Silvi \& Cuganesan, 2006). Despite the fact that volume of research is increasing, knowledge sharing remains a challenge for two obvious reasons. First, due to being tacit in nature, knowledge is not easy to transfer and second, knowledge sharing depends on the will of the holder as it is a voluntary behavior (Lin, Lyau, Tsai, Chen, $\&$ Chiu, 2010). Organizations can deal with this challenge if they could effectively manage the sources of critical knowledge, i.e., their employees. In the past, samples from the population were drawn from a single sector, either public or private, whereas, in contrast, this study has drawn random samples from both the sectors to broaden the scope of the study. Objective of this study is not only to examine the direct effect

Sukkur IBA Journal of Management and Business - SIJMB | Volume 5 No. 1 January - June 2018 @ Sukkur IBA University 
between organizational culture and knowledge sharing behavior but to identify the underlying processes that affect the direct relationship between hierarchy organizational culture and knowledge sharing behavior of teachers in higher education institutions and universities in Pakistan.

\section{Theory and Hypothesis}

\subsection{Organizational Culture and Knowledge Sharing}

Organizational culture comprises beliefs, values, norms, rituals and language shared by members of an organization. Attitudes and behaviors of employees are shaped by organizational culture (Durmusoglu, Jacobs, Zamantili Nayir, Khilji, \& Wang, 2014). The current study utilizes the Cameron and Quinn's (1999) Competing Values Framework (CVF) dimension of hierarchy culture to measure its influence on knowledge sharing behavior of organizational members.

Four dimensions of organizational culture described by K. Cameron and Quinn (1999) typology are hierarchy, adhocracy, clan and market. CVF differentiates organizational culture on two dimensions. Flexibility-control continuum is the first dimension and internal-external orientation is the second dimension. Controlled organizations are marked by predictable, unchanged and stable, whereas flexible organizations are adaptive and entrepreneurial in nature. Internal orientation means that organization focuses on achieving unity and integration, and on the other hand, an organization which is competitive and inclined to interact with external environment, is said to have an external orientation.

Knowledge sharing has been defined by Jasimuddin and Hasan (2015) as a purposive act that results in exchange of knowledge among organizational members. Jasimuddin and Hasan (2015) suggest that identifying a specific type of organizational culture that supports knowledge sharing is much important as the actual practice of knowledge transfer (Durmusoglu et al., 2014; Lopez-Nicolas \& Meroño-Cerdán, 2009). Thus, if one wants to predict the kind of behavior that would be followed by organizational members when it comes to transfer of knowledge, the type of organizational culture adopted by an organization would determine it.

Hierarchy culture supports the mechanistic governance approach through formal rules, norms, policies and procedures (Lopez-Nicolas \& Meroño-Cerdán, 2009). Paro and Gerolamo (2017) found that hierarchy culture characterized as formal and structured governs the behavior of people through rules and procedures. According to social exchange theory, knowledge sharing involves reciprocity and hierarchical relations in a work setting encompass the relational aspect of exchange process, making the later unnecessary (Serenko \& Bontis, 2016). To put it differently, advice part of a relation between a boss and a subordinate is unsuitable outside the hierarchical subordination context (Caimo \& Lomi, 2015). Employees are involved in knowledge sharing behaviors at three levels of hierarchy, i.e., immediate supervisor, group and business

Sukkur IBA Journal of Management and Business - SIJMB | Volume 5 No. 1 January - June 2018 @ Sukkur IBA University 
units. Coordination among different hierarchical levels improves knowledge sharing behavior (Sveiby \& Simons, 2002; Yang, 2007). These mechanisms reward accomplishments and greatest motivation is the job security. Effectiveness means permanence and achievement of goals. Public sector organizations are typical examples of hierarchy culture (Lopez-Nicolas \& Meroño-Cerdán, 2009). A recent study on Ghanian culture found that public sector workers in Ghana share knowledge because they want to see their organization successful, whereas Ghanian organizations are typical examples of hierarchy culture (Boateng, Dzandu, \& Tang, 2016). Another characteristic of hierarchy culture is its internal orientation where security, conformity and predictability are used to manage employees. These organizations emphasize success, permanence and stability through control and tall structures. Dependability, efficiency and low cost measure the success of an organization ( Cameron \& Quinn, 1999). Hence, this study hypothesizes that,

\section{$\mathbf{H}_{1}$ : Hierarchy organizational culture will positively influence the knowledge sharing} behavior.

\subsection{Formal Knowledge Governance Mechanism as a Mediator}

Extant literature has prompted academic research on a number of factors that facilitate or hinder knowledge sharing, but the underlying mechanisms and processes through which these factors influence knowledge sharing have not been fully addresses stimulating further scientific inquiry (Jeung, Yoon, \& Choi, 2017). Objective of this study is not only to examine the direct effect between organizational culture and knowledge sharing behavior but to identify the underlying processes that affect the direct relationship between hierarchy organizational culture and knowledge sharing behavior of employees.

Amayah (2013) examined the impact of organizational culture on knowledge sharing. Friesl, Sackmann, and Kremser (2011) studied how hierarchy effects knowledge sharing. Jasimuddin and Hasan (2015) examined the moderating effect of technology infrastructure on the relationship between formalization and sharing of knowledge. These are a few of the examples of mediating mechanisms from the literature. There could be other potential intervening variables that could affect the direct link between organizational culture and knowledge sharing behavior.

Few studies have examined the direct and/or indirect effects of organizational culture on knowledge sharing (Friesl et al., 2011; Jasimuddin \& Hasan, 2015; Amayah, 2013). There could be potential intervening variables that affect the direct link between organizational culture and knowledge sharing behavior. This study has explored a few of them.

Micro level knowledge sharing research has relied on theory of planned behavior and the social exchange theory to explain the phenomenon associated with knowledge sharing (Akhavan et al., 2015; Huang et al., 2013). Social exchange describes that

Sukkur IBA Journal of Management and Business - SIJMB | Volume 5 No. 1 January - June 2018 @ Sukkur IBA University 
employees wish to maintain long term relationships on reciprocal basis. Reciprocal relationships encourage employees to involve in knowledge transfer (Huang et al., 2013).

In case, organizational culture is not supportive for knowledge sharing, barriers would be recognized in successful knowledge transfer and knowledge sharing would thus become a chore rather than a desirable behavior an individual exhibits willingly (Aquilani, Abbate, \& Codini, 2017). Some support mechanism is recommended under these circumstances for employees to engage in KSB as organizational culture is among one of the challenges identified for successful knowledge transfer (Perrigot, Herrbach, Cliquet, \& Basset, 2017). Formal knowledge governance mechanism consists of reward and incentive systems, performance management, trainings, promotions, bonuses, and performance-based pay. All these tools are used to encourage employees to share knowledge (Huang et al., 2013; Rathi \& Given, 2017; Wang \& Noe, 2010). Extant literature has discussed the impact of knowledge governance mechanism, organizational culture and structure on knowledge sharing behavior (Huang et al., 2013; Jasimuddin \& Hasan, 2015).

The current study has introduced formal knowledge governance mechanism as a process that mediates the positive relationship between hierarchy organizational culture and knowledge sharing behavior which would help to establish that organizational culture that is usually considered a barrier in sharing knowledge would facilitate the knowledge sharing process when proper mechanisms are introduced in an organizational setup. Thus, it is proposed that,

$\mathbf{H}_{2}$ : Formal knowledge governance mechanism mediates the relationship between hierarchy organizational culture and knowledge sharing behavior.

\subsection{Knowledge Sharing Opportunity as a Mediator}

Opportunity is the extent of conduciveness of situational context to accomplish an activity Maclnnis and Jaworski (1989), and it also incorporates the enablers and barriers towards a desired behavior (Gruen, Osmonbekov, \& Czaplewski, 2006; Kettinger, Li, Davis, \& Kettinger, 2015). An important antecedent to knowledge sharing is knowledge sharing opportunity in the form of interaction between knowledge source and recipient which facilitates transfer of knowledge (Huang et al., 2013; Kang \& Kim, 2017).Workplace characteristics that facilitate or constrain certain behaviors are molded by organizational culture (Schneider, Smith, \& Sipe, 2000). Kettinger et al. (2015) considered organizational support for information technology as a form of knowledge sharing opportunity. Relational opportunities to share knowledge through interaction among members develop an environment of trust and friendship that influence the knowledge sharing behavior of organizational members (Huang et al., 2013; Ipe, 2003). Thus, when organizational members have relational opportunities to share knowledge, interpersonal relationships are improved among individuals in the organization that improve their knowledge sharing behavior (Huang et al., 2013).

Sukkur IBA Journal of Management and Business - SIJMB | Volume 5 No. 1 January - June 2018 @ Sukkur IBA University 
Hierarchy organizational culture adopts formal mechanisms (Turner \& Pennington, 2015). Opportunity to engage in knowledge sharing activities is thus influenced by structural factors including managerial support; organizational culture and design (Foss et al., 2010; Turner \& Pennington, 2015). Studies have examined conducive organizational environment facilitates employee's creativity; they are encouraged to take risks, and are allowed to exchange information openly, more likely behaviors would be examined among them (Gilson \& Shalley, 2004). Hence, we deduce that when organizational culture and support systems provide employees with the opportunities to share knowledge with other members in the organization, they will be more likely to exhibit desirable behavior, i.e., knowledge sharing behavior. Thus, it can be deduced that hierarchy organizational culture enables knowledge sharing opportunities that are important for actual knowledge sharing to occur. Therefore, it is proposed that,

$\mathbf{H}_{3}$ : Knowledge sharing opportunity mediates the relationship between hierarchy organizational culture and knowledge sharing behavior.

\subsection{Serial Multiple Mediation Effect of Formal Knowledge Governance Mechanism and Knowledge Sharing Opportunity}

Knowledge holder should be motivated by some rewards to share knowledge and the recipient should also be motivated enough to gain knowledge (Kang \& Kim, 2017). Type of reward system adopted by an organization has close association with the organizational structure, which in turn affects the pattern of desirable practices like knowledge sharing (Durmusoglu et al., 2014). Similarly, formal rules and policies are distinguishing features of mechanistic governance system that have to be strictly abided by everyone involved in an organization (Rathi \& Given, 2017). Formal support mechanisms serve as the backbone in a hierarchical setting for effective knowledge sharing among members (Perrigot et al., 2017).

Prior research has shown that employees' opportunity is one of the key mediating mechanisms between formal knowledge governance mechanism and knowledge sharing behavior (Huang et al., 2013). Few studies have examined the direct relationship between organizational culture and outcomes (Reis, Trullen, \& Story, 2016). Others have studied opportunity as a mediator between knowledge governance mechanism and knowledge sharing behavior (Huang et al. (2013)). There are inconsistent results with regard to opportunity when explaining knowledge sharing behavior. Therefore, Huang et al. (2013) have recommended that in future, studies may be undertaken that develop and test multiple level frameworks to examine knowledge sharing behavior with a diverse set of predictors. Therefore, this study has examined two intervening variables that operate sequentially between the direct relationship between hierarchy organizational culture and knowledge sharing behavior. The two mediators in the study are formal knowledge governance mechanism. Building upon social exchange theory, this study examined the mediation effects of formal knowledge governance mechanism and knowledge sharing opportunity in a sequential manner.

Sukkur IBA Journal of Management and Business - SIJMB | Volume 5 No. 1 January - June 2018 @ Sukkur IBA University 
Abbasi, S. G., \& Dastgeer, G. / Organizational Culture and Knowledge Sharing Behavior: Examining Serial

Thus, on basis of literature review, formal knowledge governance mechanism and knowledge sharing opportunity are being introduced as two mediators in this study. Therefore, it is hypothesized that,

$\mathbf{H}_{4}$ : The relationship between hierarchy organizational culture and knowledge sharing behavior is sequentially and fully mediated by formal knowledge governance mechanism and knowledge sharing opportunity.

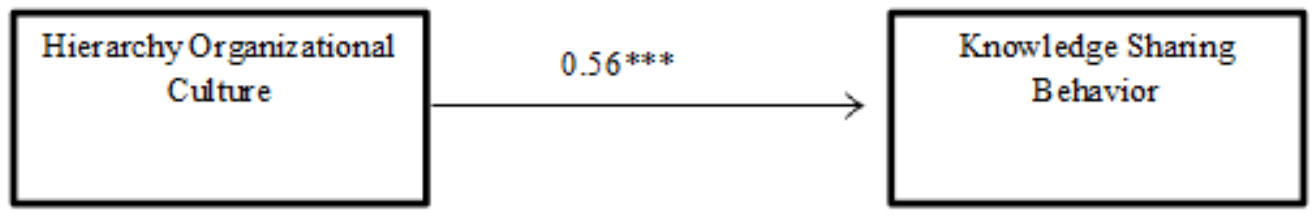

Figure 1: Relationship between independent and depended variable.

$\mathbf{H}_{1}$ : Hierarchy Organizational Culture $\rightarrow$ Knowledge Sharing Behavior: 0.56***

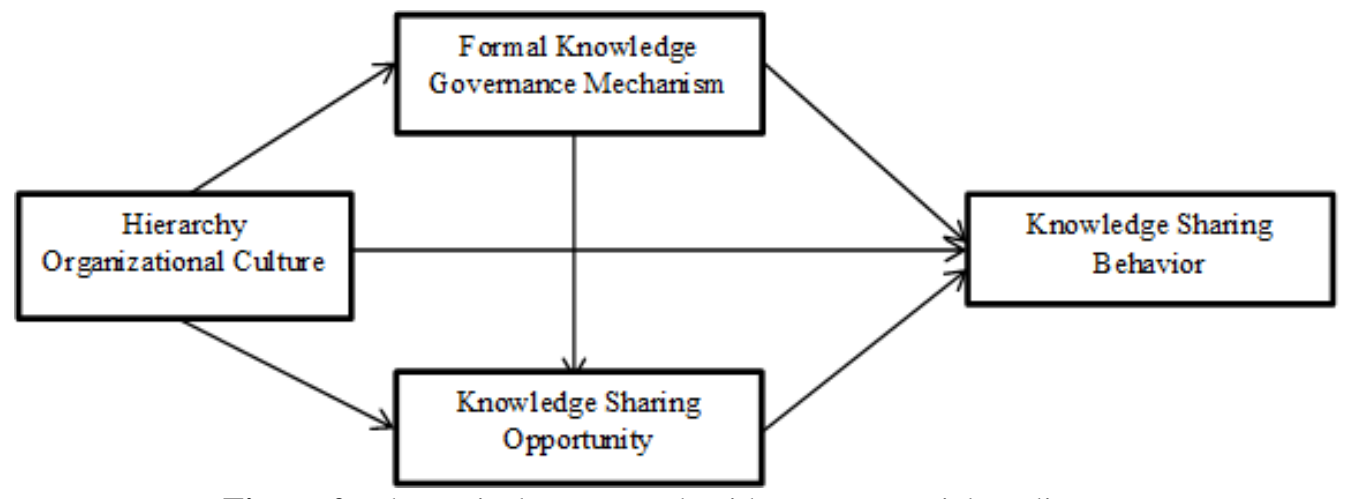

Figure 2: Theoretical Framework with two sequential mediators.

$\mathbf{H}_{2}$ : Hierarchy Organizational Culture $\rightarrow$ Formal Knowledge Governance Mechanism $\rightarrow$ Knowledge Sharing Behavior

$\mathbf{H}_{3}$ : Hierarchy Organizational Culture $\rightarrow$ Knowledge Sharing Opportunity $\rightarrow$ Knowledge Sharing Behavior

$\mathbf{H}_{4}$ : Hierarchy Organizational Culture $\rightarrow$ Formal Knowledge Governance Mechanism $\rightarrow$ Knowledge Sharing Opportunity $\rightarrow$ Knowledge Sharing Behavior

\section{Research Methodology}

3.1. Data Collection and Sample Characteristics

Data for the current study was collected from Higher Education sector of Pakistan. Social identity theory has been deemed successful in explaining individual attitudes and behaviors when sample is drawn from a collectivistic culture. According to Hofstede 
(1984), Pakistan represents a collectivistic society. It means employees share strong identity with their organization making the impact of typical hierarchical culture on knowledge sharing behavior of employees more expressive. Pakistani employees are the most suitable population to choose subjects from because it provides a distinct setting with significant scope for the study.

The collectivistic approach is manifested in relationships among individuals in different roles. An undesirable behavior may put the person in an awkward situation leading to embarrassment and shame. So, individuals are expected to take responsibility on behalf of fellow members. Management works on the principle that management is for groups not for individuals, hence, in-group and out-group approaches may be practised in the recruitment, selection and hiring practices that indirectly affect the behaviors exhibited by employees (Khilji, 2004).

Higher education is an example of open system that absorbs the general environment trends from outside and creates and transfers knowledge to the outside (Amayah, 2013). Thus, the nature of this sector makes it a potential area to be explored in the context of knowledge sharing behavior.

Population for the study consisted of all faculty members/teachers in public and private sector universities and Higher Education Institutions in the cities of Rawalpindi and Islamabad. Survey was administered personally to all the respondents in the sample. Universities were randomly chosen from both the sectors using stratified random sampling. Survey was distributed to all the four levels of faculty members, i.e., lecturers, assistant professors, associate professors and professors. 400 questionnaires were administered among 12 universities/HEIs. 290 were returned and the size of the useable survey was 269 making a return rate of $67.25 \%$. along with other measures to ensure the quality of data. Those having less than one year of experience with their current organization were not included in the sample as they might not be knowledgeable about the culture, structure and policies of their organization so well.

Among the demographic variables, age, gender, sector, designation, qualification and experience were measured. Most of the respondents were male constituting $67.3 \%$ of the sample, $64.7 \%$ of the total sample were in the age bracket of 26-35 years, public sector respondents were $67.3 \%$ of the sample and majority of the respondents, i.e., $76.6 \%$ were either lecturers or assistant professors. Minimum experience was at least one year with the current organization and minimum qualification was Masters/MS degree or equivalent.

\subsection{Definitions of Terms and Concepts and Measurement Scales Utilized 3.2.1. Hierarchy organizational culture}

This is a type of organizational culture that is based on structures and controls ad focus on efficiency, stability and doing things right ( Cameron \& Quinn, 2011). Organizational Culture Assessment Instrument (OCAI) developed by (Cameron \& 
Quinn, 2011) was used to measure hierarchy organizational culture consisting of six items.

\subsubsection{Formal Knowledge Governance Mechanism}

It refers to the performance evaluations, incentives and other reward systems, promotion bonuses, performance based pay, trainings developed by organization to support knowledge sharing (Huang et al. (2013); Wang and Noe (2010)).This study used the scale adopted by Huang et al. (2013) and developed by Björkman, BarnerRasmussen, and $\mathrm{Li}$ (2004) to measure formal knowledge governance mechanism with three items.

\subsubsection{Knowledge Sharing Opportunity}

It denotes an environmental situation that demonstrates a favorable juncture of circumstances for enabling action (Siemsen, Roth, \& Balasubramanian, 2008). Three item scale was used to measure knowledge sharing opportunity.

\subsubsection{Knowledge Sharing Behavior}

Knowledge sharing behaviors represent a set of behaviors in which information is exchanged and support is provided to others as explained by (Collins \& Smith, 2006). Knowledge sharing behavior was used measuring three item scale adopted from (Bock, Zmud, Kim, \& Lee, 2005). The scale items include e.g., organizational employees share business manuals, models, and methodologies with each other. The survey was floated in the original language, i.e., English and minimum qualification of the respondents was Master/MS degree. Constructs were measured using 7-point Likert type scale as the original scales were developed to measure responses on 7-point interval scale. Three HRD and HRM scholars reviewed the questionnaire before administering that confirmed the face validity of the scales used in the study.

\section{Data Analysis and Results}

Table 1: Mean, Standard Deviation and Correlations

\begin{tabular}{llllll}
\hline \multicolumn{2}{l}{} & 1 & 2 & 3 & 4 \\
\hline 1 & Hierarchy organizational culture & 0.71 & & & \\
2 & $\begin{array}{l}\text { Formal knowledge governance } \\
\text { mechanism }\end{array}$ & $0.64^{* *}$ & 0.59 & & \\
& & & & & \\
3 & Knowledge sharing opportunity & $0.70^{* * *}$ & $0.73^{* * *}$ & 0.85 & \\
4 & Knowledge sharing behavior & $0.59^{* *}$ & $0.67^{* *}$ & $0.67^{* *}$ & 0.63 \\
& Mean & 4.99 & 4.97 & 4.71 & 4.89 \\
& SD & 1.29 & 1.42 & 1.69 & 1.28 \\
Min & 1 & 1 & 1 & 1.71 \\
Max & 7 & 7 & 7 & 7 \\
AVE & 0.94 & 0.81 & 0.94 & 0.92 \\
CR & 0.94 & 0.81 & 0.94 & 0.92 \\
\hline
\end{tabular}

Sukkur IBA Journal of Management and Business - SIJMB | Volume 5 No. 1 January - June 2018 @ Sukkur IBA University 
$\mathrm{CR}$ is the composite reliability; AVE (average variance extracted) values are given on the diagonal; $* * \mathrm{p}<0.01$.

Table 1 shows the mean, standard deviation, minimum, maximum, average variance extracted and composite reliability for the study variables. Common validation process was used to assess the unidimensionality, reliability and validity of the measures involved. Chronbach alpha coefficient gave the reliability values for all latent constructs. All the values were fairly above the threshold value of 0.7. To further confirm the unidimensionality, EFA was done. Convergent validity and discriminant validity was assessed through CFA. Measurement model fitted the data well in CFA. $\mathrm{t}$-values corresponding to factor loadings were greater than 1.96 and factor loadings exceeded 0.7. It reveals the existence of convergent validity. There exists high composite reliability as ranging from 0.81 to 0.94 in Table 1 . Discriminant validity was confirmed as Average Variance Extracted (AVE) was more than the correlation between any given construct and the other.

Podsakoff, MacKenzie, and Podsakoff (2012) recommended various measures to deal with the issue of common method bias (CMB) for studies that involve self-report measures. Anonymity of sample respondents, improved item phrasing and evaluation apprehension reduction are a few of the procedural measures taken to deal with CMB. Harman's one factor analytic test ensured that CMB was not involved. Total variance explained in the test was below $47 \%$ and variance below 50\%, an indicator that CMB was not an issue in this study. Assumptions of Structural Equation Modeling (SEM) were checked and tested before running the structural model. Assumptions are normality and linearity of data, no multicollinearity among variables and homoscedasticity.

\subsection{Hypothesis Testing}

The model hypothesized, thus explained $53.1 \%$ variance in formal knowledge governance mechanism, $72.8 \%$ of knowledge sharing opportunity, and $60.6 \%$ in knowledge sharing behavior. As a first step towards testing the hypothesis that formal knowledge governance mechanism and knowledge sharing opportunity would fully and sequentially mediate the relationship between independent variable and dependent variable, direct relationship between hierarchy organizational culture and knowledge sharing behavior was estimated. Hierarchy organizational culture was found to be positively related with knowledge sharing behavior, $(b=0.56, p<0.001)$ and hence, Hypothesis 1 was accepted.

Sukkur IBA Journal of Management and Business - SIJMB | Volume 5 No. 1 January - June 2018 @ Sukkur IBA University 
Abbasi, S. G., \& Dastgeer, G. / Organizational Culture and Knowledge Sharing Behavior: Examining Serial

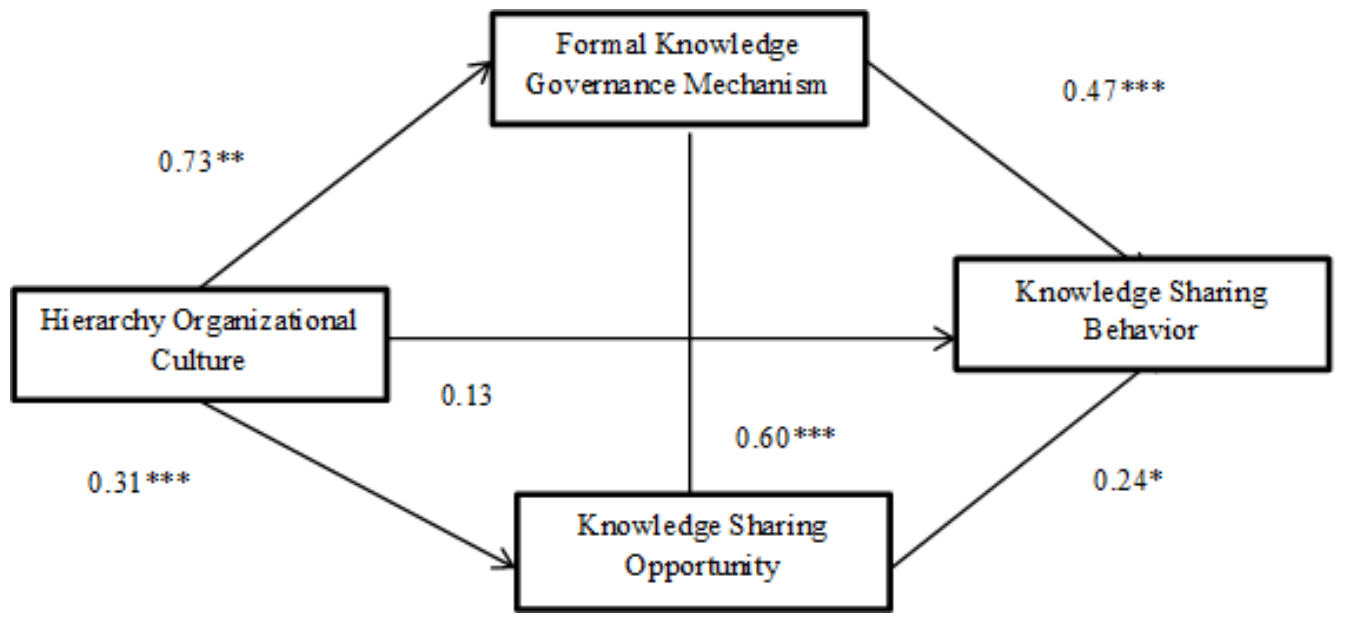

Figure 3: Path coefficients, $* * * \mathrm{p}<0.001,{ }^{* *} \mathrm{p}<0.01,{ }^{*} \mathrm{p}<0.05$

$\mathbf{H}_{2}$ : Hierarchy Organizational Culture $\rightarrow$ Formal Knowledge Governance Mechanism $\rightarrow$ Knowledge Sharing Behavior: 0.35*

$\mathbf{H}_{3}$ : Hierarchy Organizational Culture $\rightarrow$ Knowledge Sharing Opportunity $\rightarrow$ Knowledge Sharing Behavior: 0.27*

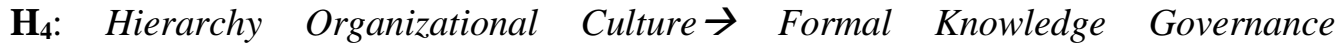
Mechanism $\rightarrow$ Knowledge Sharing Opportunity $\rightarrow$ Knowledge Sharing Behavior: 0.13

Table 2: Path Coefficients, Direct and Indirect Effects for Mediation Models

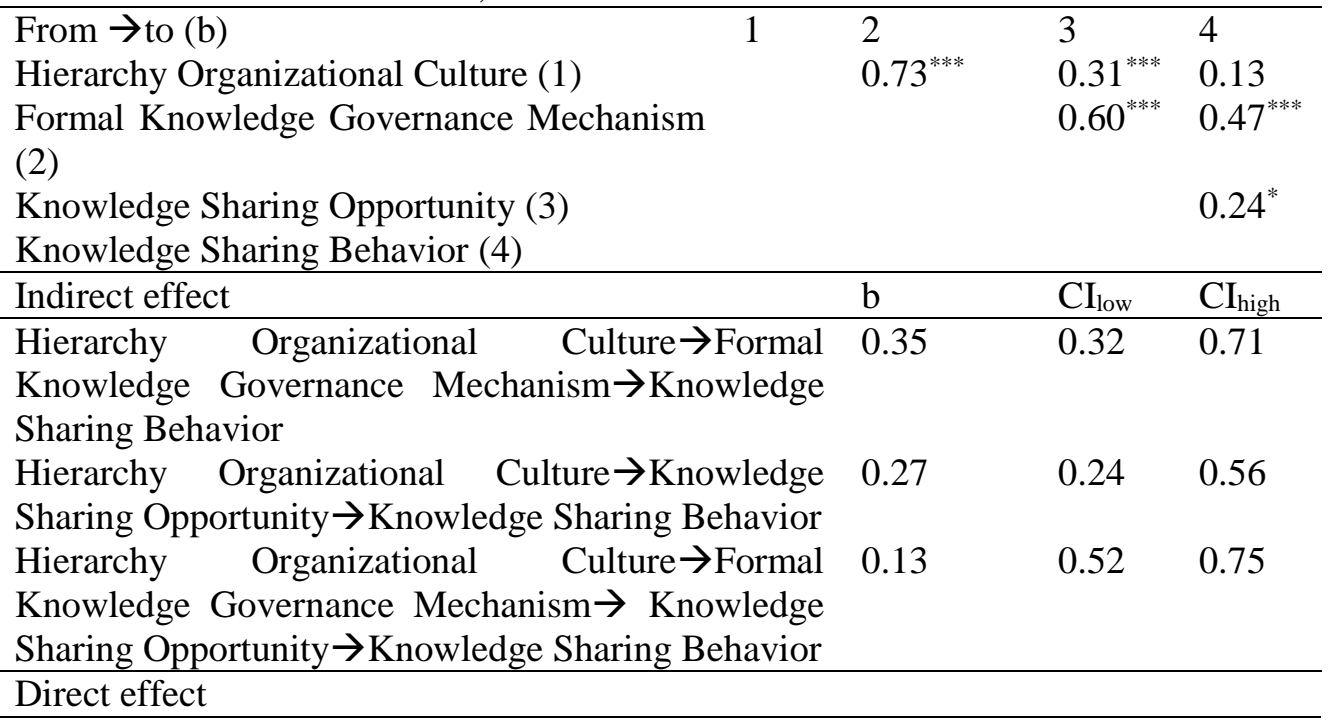


Abbasi, S. G., \& Dastgeer, G. / Organizational Culture and Knowledge Sharing Behavior: Examining Serial

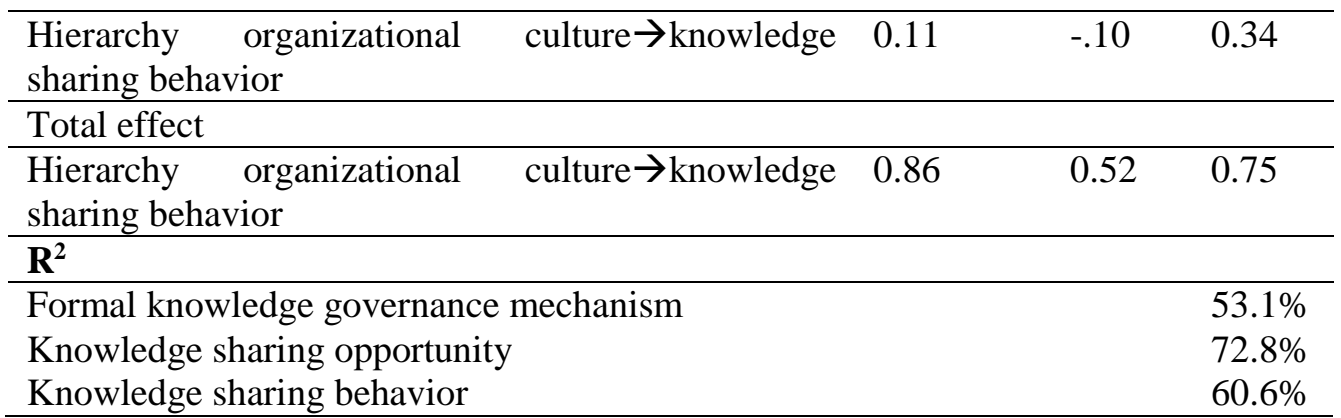

Two-tailed tests for path coefficients with $95 \%$ confidence level, ${ }^{* * *} \mathrm{p}<0.001$

$\chi^{2}{ }_{(139)}=273.356, \mathrm{p}<0.001, \mathrm{CMIN} / \mathrm{DF}=1.97, \mathrm{TLI}=0.97, \mathrm{IFI}=0.97, \mathrm{RFI}=0.93, \mathrm{NFI}=0.94$, $\mathrm{CFI}=0.97$, RMSEA $=0.06$.

Table 2 gives the coefficients of structural model coefficients and three path-mediated model. By utilizing this approach, indirect effects of both the mediators can be separated. Hypothesized model offered the acceptable fit to the model. $\chi^{2}(139)=273.356$, $\mathrm{p}<0.001, \mathrm{CMIN} / \mathrm{DF}=1.97, \mathrm{TLI}=0.97, \mathrm{IFI}=0.97, \mathrm{RFI}=0.93, \mathrm{NFI}=0.94, \mathrm{CFI}=0.97$, RMSEA $=0.06$.

Six paths model was investigated as in the Figure 3 to find out the mediation effects. Indirect effects were estimated with bootstrapping, 95\% confidence interval, and biascorrected $(\mathrm{N}=5000)$. Hypothesis 2 proposed that formal knowledge governance mechanism mediates the relationship between hierarchy organizational culture and knowledge sharing behavior. The indirect effect of hierarchy organizational culture on knowledge sharing behavior through formal knowledge governance mechanism was moderate $(b=0.35)$, with $95 \%$ CI $[0.320 .71]$, a bootstrap estimate, and it was statistically significant. Thus, confirming indirect effect, and hypothesis 2 was accepted. Hypothesis 3 proposed that knowledge sharing opportunity mediates the path between hierarchy organizational culture and knowledge sharing behavior and it was supported ( $b=0.27,95 \%$ CI $[0.240 .56])$. Serial multiple mediation effect through formal knowledge governance mechanism and knowledge sharing opportunity was measured to test Hypothesis 4. The indirect effect of hierarchy organizational culture on knowledge sharing behavior through formal knowledge governance mechanism and knowledge sharing opportunity was found to be statistically insignificant $(b=0.13,95 \%$ CI [-.1 0.34$]$ ). Thus, we can say that the positive relationship between hierarchy organizational culture and knowledge sharing behavior was fully and sequentially mediated by formal knowledge governance mechanism and knowledge sharing opportunity.

\section{Conclusion}

Drawing upon social exchange theory, purpose of the study was to examine how hierarchy organizational culture impact knowledge sharing behavior through formal knowledge governance mechanism and knowledge sharing opportunity respectively, 
and also examined the influence of hierarchy organizational culture on knowledge sharing behavior through formal knowledge governance mechanism and knowledge sharing opportunity.

The study showed that there is a positive relationship between hierarchy organizational culture knowledge sharing behavior of employees, providing support to the idea that hierarchy organizational culture has a positive influence on knowledge sharing behavior leading to Hypothesis 1 being accepted. When there is full mediation, the direct effect of independent variable on dependent variable becomes insignificant. It means that in presence of mediating mechanism, independent variable will no longer affect dependent variable and all the change in dependent variable would be due to intervening or mediating variable. If the effect of independent variable still remains significant after a mediating mechanism is introduced, we conclude that there is partial mediation. Partial mediation signifies that independent variable still has some effect on dependent variable when a mediating process is introduced between independent and dependent variable (Baron and Kenny (1986); Preacher and Hayes (2008)). There was full mediation when the two mediators were introduced in the model of this study as shown by the results of hypothesis 2.3 and 4. To further elaborate the findings, we can say that the positive relationship between hierarchy organizational culture and knowledge sharing behavior is fully and serially multiple mediated by formal knowledge governance mechanism and knowledge sharing opportunity, which supports Hypothesis 4. It is a major finding and contribution of this study that formal knowledge governance mechanism and knowledge sharing opportunity play an important and significant role as sequential mediators between hierarchy organizational culture and knowledge sharing behavior, respectively. It means that in presence of either formal knowledge governance mechanism or knowledge sharing opportunity, there would be no effect of hierarchy organizational culture on knowledge sharing behavior of employees when these mechanisms are introduced separately as supported by hypotheses 2 and 3 . Furthermore, when both mediators are simultaneously introduced in the model in a sequential manner, there is no effect of hierarchy culture on knowledge sharing behavior. It signifies that the only change in knowledge sharing behavior is due to governance mechanism utilized by an organization and the knowledge sharing opportunity it provides to them. When these mechanisms are present, the impact of culture is minimized and there is no considerable change in knowledge sharing behavior of employees due to organizational culture. This is in support to hypothesis 4 .

\subsection{Theoretical Implications}

This study has a contribution to several streams of research. First, it introduced two new mediating mechanisms between the direct relationship of hierarchy organizational culture and knowledge sharing behavior, enriching the organizational culture and knowledge sharing behavior literature. An important implication follows that the only driving force to share knowledge in the organizations is not the cultural norms and

Sukkur IBA Journal of Management and Business - SIJMB | Volume 5 No. 1 January - June 2018 @ Sukkur IBA University 
values, but equally important are the knowledge sharing mechanisms and opportunities provided that employees can avail in context of knowledge sharing.

Secondly, in extant literature, the most common theory employed to explain knowledge sharing and its predictors is theory of planned behavior. But this study contributed to the literature by building theory on social identity and social exchange streams.

Third, this study protracted the Huang et al. (2013) model by introducing hierarchy organizational culture as a predictor of formal knowledge governance. Introduction of two mediators further extended the Huang et al. (2013) model.

Fourth, relationships among knowledge governance mechanisms, opportunities to share knowledge and knowledge sharing behavior are not established in a single direction and results are inconsistent in previous studies. This study is a significant contribution to confirm the positive associations between knowledge sharing behavior and its predictors.

Finally, this study contributed to organizational behavior literature by examining the relationship between knowledge sharing behavior and its predictors. The findings imply that organizational culture improves knowledge sharing behavior of employees but formal knowledge governance mechanism combined with knowledge sharing opportunity is important to enhance knowledge sharing behavior of employees.

\subsection{Managerial Implications}

This study has significant contributions for practitioners. This study kindles the practitioners and managers to re-consider the role formal knowledge governance mechanism can play for creating synergy to upsurge knowledge sharing opportunities that contribute to improvement in knowledge sharing behavior.

Second, if managers are aware of the fact that existing organizational culture is not aligned with the knowledge governance mechanisms, employees would have lesser opportunities to share knowledge, and as a consequence, they may not display knowledge sharing behavior.

Third, in previous studies, it has been found that organizational climate, knowledge governance mechanisms and knowledge sharing opportunity shape the knowledge sharing behavior (Huang et al., 2013; Titi Amayah, 2013). Therefore, managers should design and develop organizational cultures that exploit the full advantages of knowledge governance mechanisms to provide opportunities to share knowledge that consequently would be observed as knowledge sharing behavior among organizational members.

Fourth, Pakistani organizations are representative of long hierarchies and structures are more pronounced in Higher Education institutions and universities in both public and

Sukkur IBA Journal of Management and Business - SIJMB | Volume 5 No. 1 January - June 2018 @ Sukkur IBA University 
private sectors. Contrary to the common understanding that centralization, and formalized structures are a barrier to effective knowledge sharing Amayah (2013), others have found that culture also facilitates knowledge sharing (Durmusoglu et al., 2014). This study also found that hierarchy organizational culture and formal knowledge governance mechanism facilitate employees in providing opportunities to share their knowledge, expertise, skills, etc. so that they exhibit knowledge sharing behavior.

Finally, as a result of recent reforms, higher education sector has been revived by the establishment of Higher Education Commission (HEC), Medium Term Development Framework and establishment of Quality Enhancement Cell. Financial, procurement and administrative procedures have been streamlined. Practitioners and managers in higher education sector can develop knowledge governance mechanisms in their hierarchy cultures that would create more knowledge sharing opportunities for employees and contribute towards better knowledge sharing among organizational members.

\subsection{Limitations and Future Research}

Contributions of this study should be acknowledged while allowing the limitations to be realized that lead towards future directions. The first limitation of the study is its self-report measures and cross-sectional nature of data collected. Although common method bias has been treated by taking steps as recommended by Podsakoff et al. (2012), in future, it could be avoided by collecting longitudinal data at two points in time.

Second limitation is the factor of social desirability bias that may have contaminated the data. It is a major cause of shared method variance (Hur, Moon, \& Ko, 2016; Podsakoff et al., 2012). This issue can be overcome by measuring social desirability bias directly in future studies.

Third, as the target population was faculty members in higher education sector of Pakistan, it has low external validity. Samples may be drawn from other industries like manufacturing, services, IT, medical to test the external validity of the findings. Fourth, although individual behavior is manifested in organizational behavior, this study did not adopt any controls for organizational effects that might be involved in individual effects. A remedy that might be suggested for future studies is to employ a multi-level approach such as hierarchical linear modeling. In-depth interviews may be conducted a part of qualitative research in future studies.

Fifth, the study may be replicated with the same latent constructs but the unit of analysis could be teams or groups to examine how this mechanism operates when individuals have to perform collectively and when joint opportunities are provided to share knowledge by organizational culture through employing knowledge governance mechanisms.

Sukkur IBA Journal of Management and Business - SIJMB | Volume 5 No. 1 January - June 2018 @ Sukkur IBA University 
Finally, to retain parsimony, no boundary conditions are specified in this study, and they may have potential positive or negative effect on the relationship between organizational culture and knowledge sharing behavior. Boundary conditions may be specified by contextual variables like leader-member-exchange, loyalty, trust, leadership style, and/or different fit measures.

\section{References}

Akhavan, P., Hosseini, S. M., Abbasi, M., \& Manteghi, M. (2015). Knowledge-sharing determinants, behaviors, and innovative work behaviors: An integrated theoretical view and empirical examination. Aslib Journal of Information Management, 67(5), 562-591.

Anne Crowne, K. (2009). Enhancing knowledge transfer during and after international assignments. Journal of Knowledge Management, 13(4), 134-147.

Aquilani, B., Abbate, T., \& Codini, A. (2017). Overcoming cultural barriers in open innovation processes through intermediaries: a theoretical framework. Knowledge Management Research \& Practice, 15(3), 447-459.

Ardichvili, A. (2008). Learning and knowledge sharing in virtual communities of practice: Motivators, barriers, and enablers. Advances in developing human resources, 10(4), 541-554.

Argote, L., McEvily, B., \& Reagans, R. (2003). Managing knowledge in organizations: An integrative framework and review of emerging themes. Management science, 49(4), 571-582.

Baron, R. M., \& Kenny, D. A. (1986). The moderator-mediator variable distinction in social psychological research: Conceptual, strategic, and statistical considerations. Journal of personality and social psychology, 51(6), 1173.

Björkman, I., Barner-Rasmussen, W., \& Li, L. (2004). Managing knowledge transfer in MNCs: The impact of headquarters control mechanisms. Journal of international business studies, 35(5), 443-455.

Boateng, H., Dzandu, M. D., \& Tang, Y. (2016). Knowledge sharing among employees in Ghanaian Industries: The role of transformational leadership style and communal organizational culture. Business Information Review, 33(3), 145154.

Bock, G.-W., Zmud, R. W., Kim, Y.-G., \& Lee, J.-N. (2005). Behavioral intention formation in knowledge sharing: Examining the roles of extrinsic motivators, social-psychological forces, and organizational climate. MIS quarterly, 87-111.

Cabrera, E. F., \& Cabrera, A. (2005). Fostering knowledge sharing through people management practices. The International Journal of Human Resource Management, 16(5), 720-735.

Caimo, A., \& Lomi, A. (2015). Knowledge sharing in organizations: A Bayesian analysis of the role of reciprocity and formal structure. Journal of management, $41(2), 665-691$.

Sukkur IBA Journal of Management and Business - SIJMB | Volume 5 No. 1 January - June 2018 @ Sukkur IBA University 
Cameron, K., \& Quinn, R. (1999). Diagnosing and Changing Organizational Culture: Based on the.

Cameron, K. S., \& Quinn, R. E. (2011). Diagnosing and changing organizational culture: Based on the competing values framework: John Wiley \& Sons.

Collins, C. J., \& Smith, K. G. (2006). Knowledge exchange and combination: The role of human resource practices in the performance of high-technology firms. Academy of management Journal, 49(3), 544-560.

Durmusoglu, S., Jacobs, M., Zamantili Nayir, D., Khilji, S., \& Wang, X. (2014). The quasi-moderating role of organizational culture in the relationship between rewards and knowledge shared and gained. Journal of Knowledge Management, 18(1), 19-37.

Foss, N. J., Mahoney, J. T., \& De Pablos, P. O. (2010). Knowledge governance: contributions and unresolved issues. International Journal of Strategic Change Management, 2(4), 263-268.

Friesl, M., Sackmann, S. A., \& Kremser, S. (2011). Knowledge sharing in new organizational entities: The impact of hierarchy, organizational context, micropolitics and suspicion. Cross Cultural Management: An International Journal, 18(1), 71-86.

Gilson, L. L., \& Shalley, C. E. (2004). A little creativity goes a long way: An examination of teams' engagement in creative processes. Journal of management, 30(4), 453-470.

Gruen, T. W., Osmonbekov, T., \& Czaplewski, A. J. (2006). eWOM: The impact of customer-to-customer online know-how exchange on customer value and loyalty. Journal of Business research, 59(4), 449-456.

Hofstede, G. (1984). Culture's consequences: International differences in work-related values (Vol. 5): sage.

Huang, M.-C., Chiu, Y.-P., \& Lu, T.-C. (2013). Knowledge governance mechanisms and repatriate's knowledge sharing: the mediating roles of motivation and opportunity. Journal of Knowledge Management, 17(5), 677-694.

Hur, W.-M., Moon, T.-W., \& Ko, S.-H. (2016). How employees' perceptions of CSR increase employee creativity: Mediating mechanisms of compassion at work and intrinsic motivation. Journal of Business Ethics, 1-16.

Husted, K., Michailova, S., Minbaeva, D. B., \& Pedersen, T. (2012). Knowledgesharing hostility and governance mechanisms: an empirical test. Journal of Knowledge Management, 16(5), 754-773.

Ipe, M. (2003). Knowledge sharing in organizations: A conceptual framework. Human resource development review, 2(4), 337-359.

Jasimuddin, S. M., \& Hasan, I. (2015). Organizational culture, structure, technology infrastructure and knowledge sharing. Vine, 45(1), 67-88.

Jeung, C.-W., Yoon, H. J., \& Choi, M. (2017). Exploring the affective mechanism linking perceived organizational support and knowledge sharing intention: a moderated mediation model. Journal of Knowledge Management, 21(4), 946960.

Sukkur IBA Journal of Management and Business - SIJMB | Volume 5 No. 1 January - June 2018 @ Sukkur IBA University 
Kang, M., \& Kim, B. (2017). Motivation, opportunity, and ability in knowledge transfer: a social network approach. Knowledge Management Research \& Practice, 15(2), 214-224.

Kettinger, W. J., Li, Y., Davis, J. M., \& Kettinger, L. (2015). The roles of psychological climate, information management capabilities, and IT support on knowledgesharing: an MOA perspective. European Journal of Information Systems, 24(1), 59-75.

Khilji, S. E. (2004). Whither tradition? Evidence of generational differences in HR satisfaction from Pakistan. International Journal of Cross Cultural Management, 4(2), 141-156.

Lin, C.-P., Lyau, N.-M., Tsai, Y.-H., Chen, W.-Y., \& Chiu, C.-K. (2010). Modeling corporate citizenship and its relationship with organizational citizenship behaviors. Journal of Business Ethics, 95(3), 357-372.

Liu, N.-C., \& Liu, M.-S. (2011). Human resource practices and individual knowledgesharing behavior-an empirical study for Taiwanese R\&D professionals. The International Journal of Human Resource Management, 22(04), 981-997.

Lopez-Nicolas, C., \& Meroño-Cerdán, Á. L. (2009). The impact of organizational culture on the use of ICT for knowledge management. Electronic Markets, 19(4), 211.

Maclnnis, D. J., \& Jaworski, B. J. (1989). Information processing from advertisements: Toward an integrative framework. The Journal of marketing, 1-23.

Nonaka, I. (1994). News in contraception. Medline Rows With NULL issns Will Point To This, 5(3), 14-14.

Nonaka, I., Byosiere, P., Borucki, C. C., \& Konno, N. (1994). Organizational knowledge creation theory: a first comprehensive test. International Business Review, 3(4), 337-351.

Paro, P. E. P., \& Gerolamo, M. C. (2017). Organizational culture for lean programs. Journal of Organizational Change Management, 30(4), 584-598.

Perrigot, R., Herrbach, O., Cliquet, G., \& Basset, G. (2017). Know-how transfer mechanisms in franchise networks: a study of franchisee perceptions. Knowledge Management Research \& Practice, 15(2), 272-281.

Podsakoff, P. M., MacKenzie, S. B., \& Podsakoff, N. P. (2012). Sources of method bias in social science research and recommendations on how to control it. Annual review of psychology, 63, 539-569.

Preacher, K. J., \& Hayes, A. F. (2008). Asymptotic and resampling strategies for assessing and comparing indirect effects in multiple mediator models. Behavior research methods, 40(3), 879-891.

Rathi, D., \& Given, L. M. (2017). Non-profit organizations' use of tools and technologies for knowledge management: a comparative study. Journal of Knowledge Management, 21(4), 718-740.

Reis, G., Trullen, J., \& Story, J. (2016). Perceived organizational culture and engagement: the mediating role of authenticity. Journal of Managerial Psychology, 31(6), 1091-1105.

Sukkur IBA Journal of Management and Business - SIJMB | Volume 5 No. 1 January - June 2018 @ Sukkur IBA University 
Schneider, B., Smith, D. B., \& Sipe, W. P. (2000). Personnel selection psychology: Multilevel considerations.

Serenko, A., \& Bontis, N. (2016). Negotiate, reciprocate, or cooperate? The impact of exchange modes on inter-employee knowledge sharing. Journal of Knowledge Management, 20(4), 687-712.

Siemsen, E., Roth, A. V., \& Balasubramanian, S. (2008). How motivation, opportunity, and ability drive knowledge sharing: The constraining-factor model. Journal of Operations Management, 26(3), 426-445.

Silvi, R., \& Cuganesan, S. (2006). Investigating the management of knowledge for competitive advantage: a strategic cost management perspective. Journal of intellectual capital, 7(3), 309-323.

Singh Sandhu, M., Kishore Jain, K., \& Umi Kalthom bte Ahmad, I. (2011). Knowledge sharing among public sector employees: evidence from Malaysia. International Journal of Public Sector Management, 24(3), 206-226.

Sveiby, K.-E., \& Simons, R. (2002). Collaborative climate and effectiveness of knowledge work-an empirical study. Journal of Knowledge Management, 6(5), 420-433.

Titi Amayah, A. (2013). Determinants of knowledge sharing in a public sector organization. Journal of Knowledge Management, 17(3), 454-471.

Turner, T., \& Pennington, W. W. (2015). Organizational networks and the process of corporate entrepreneurship: how the motivation, opportunity, and ability to act affect firm knowledge, learning, and innovation. Small Business Economics, 45(2), 447-463.

Wang, S., \& Noe, R. A. (2010). Knowledge sharing: A review and directions for future research. Human resource management review, 20(2), 115-131.

Yang, D. (2010). How does knowledge sharing and governance mechanism affect innovation capabilities?-from the coevolution perspective. International Business Research, 4(1), 154.

Yang, J.-t. (2007). The impact of knowledge sharing on organizational learning and effectiveness. Journal of Knowledge Management, 11(2), 83-90.

Yusof, Z. M., Ismail, M. B., Ahmad, K., \& Yusof, M. M. (2012). Knowledge sharing in the public sector in Malaysia: a proposed holistic model. Information Development, 28(1), 43-54. 